\title{
Nature Conservation Technology for Producing Slag-Foam Glass as a Structural and Thermal Insulating Material
}

\author{
Natalia Gilyazidinova ${ }^{1}$, Nadezhda Rudkovskaya $^{1}$, Tatiana Santalova ${ }^{1, *}$ \\ ${ }^{1}$ T.F. Gorbachev Kuzbass State Technical University, 650000, 28 Vesennyaya St., Kemerovo, Russia
}

\begin{abstract}
The purpose of the research is to determine the starting material composition, the conditions for its heat treatment and operation, and also the development of the recommendations on the technology of manufacturing and use of slag-foam glass as a structural and thermal insulation material for low-rise construction. Research and development of the composition and technology of ferrosilicate dust - a secondary product of the Novokuznetsk ferroalloy plant and Kemerovo chemical enterprises - slag-foam glass production, were carried out taking into account the need for recycling of waste generated during the production process. The liquid sodium glass production waste is a mixture of ferrosilicate dust that is not completely exhausted in the reactors and an aqueous $\mathrm{Na}_{2} \mathrm{OSiO}_{2}$ solution. Its density varies from $1.2 \mathrm{~g} / \mathrm{cm}^{3}$ to $1.5 \mathrm{~g} / \mathrm{cm}^{3}$, and the binding properties are extremely unstable, they depend on the soluble glass and water ratio in the waste. The use of this material as the basis for the production of structural and thermal insulating slag-foam glass with the stable strength index, the average density and the long-term durability is quite relevant.
\end{abstract}

\section{Introduction}

At present, the theoretical bases of the processes of hydration and hardening of slag-alkali binders based on the adhesive properties of alkali metal compounds - sodium, potassium, cesium, etc., are widely used in construction. High modulus (low-basic) glasses are alkaline compounds used as air binders for plastering and painting works in combination with various hardeners. Also, liquid sodium glass with hardener - calcium chloride is used to fix the soil, and during this interaction, the water-insoluble solid silicic acid gel is formed. Sodium liquid glass is also used for the production of acid-resistant cements and concretes, as well as for the production of slag-and-ash wall stones and concretes. The formed solid body has a certain water and weather resistance. Its strength ranges from 3 to $12 \mathrm{MPa}$, and the average density is from 600 to $1900 \mathrm{~kg} / \mathrm{m}^{3}$.

The idea of this work is to combine the liquid glass production waste with Kuzbass energy industry fuel waste to obtain structural and thermal insulation concrete.

\footnotetext{
${ }^{*}$ Corresponding author: $\underline{\text { santalovatn@ } @ \text { kuzstu.ru }}$
} 
The relevance of this work also lies in the fact that in the Kuzbass region there is a shortage of quality natural aggregates for the production of concretes. At the same time, there are a large number of annually accumulated production wastes on the enterprises' dumps, which can be used as aggregates for concrete. Granulated clinkers have a number of advantages and, therefore, it is of interest to use them together with the liquid sodium glass production waste to produce the efficient thermal insulating concretes that meet the requirements of low-rise construction.

\section{Materials and methods}

In the process of research conducting the following tasks were solved:

1) determination of the starting material composition, the conditions for its heat treatment and operation;

2) determination of the required physical and mechanical characteristics of the material;

3) development of recommendations on the technology of manufacturing and use of slagfoam glass as a structural and thermal insulation material.

The following materials were used as aggregates:

- fly ash of Kemerovo State District Power Station of the average $1030 \mathrm{~kg} / \mathrm{m}^{3}$ density, the true $2210 \mathrm{~kg} / \mathrm{m}^{3}$ density, having the specific surface area of $1800 \mathrm{~cm}^{2} / \mathrm{g}$ and the $2.25 \%$ loss on ignition.

- ash and slag mixture of Novo-Kemerovo Central Heating and Power Plant of the average $1121 \mathrm{~kg} / \mathrm{m}^{3}$ density, the true $2040 \mathrm{~kg} / \mathrm{m}^{3}$ density, which has the $3.0 \%$ loss on ignition.

- ferrosilicate dust - a secondary product of Novokuznetsk ferroalloy plant of the average $200 \mathrm{~kg} / \mathrm{m}^{3}$ density, the $008-1.3 \%$ sieve residue grinding fineness.

300 brand Portland cement from Topkinsky cement plant was used as a clinker binder. The standard sodium liquid glass according to State standard 13078-81 was also used. In appearance, it is a thick liquid of light gray color with a density of $1.44 \mathrm{~g} / \mathrm{cm}^{3}$.

In order to obtain the product of the required density, as an experiment, the ferrosilicate dust was diluted with water and added to the liquid glass waste. As a result of the analysis, it was found that when the water is added to the liquid glass, the average solution density decreases, and when the liquid glass is introduced, it stabilizes after reaching the value of $1.41-1.42 \mathrm{~g} / \mathrm{cm}^{3}$. To obtain more complete information on the suitability of sodium ferrosilicate and its production waste, the following studies were carried out.

The nature of the blow out of the materials was studied without introducing aggregates into their composition. Liquid glass, waste or a combination thereof was placed in a drying cabinet at a temperature of $180^{\circ} \mathrm{C}$ for $15-18$ hours. The blow out nature and the formed pores were determined visually. And to determine the water content in the liquid glass or its production waste, the container with the product was subjected to evaporation in an oven at a temperature of $170^{\circ} \mathrm{C}$.

From the analysis of the research results it is established that the soluble sodium ferrosilicate composition contains up to $24 \%$, and its production waste up to $54 \%$ of water easily removed by evaporation. During the storage (long-term curing) of the soluble sodium ferrosilicate production waste, its density increases, evidently due to water evaporation and stratification. The change in the properties of the $1.34 \mathrm{~g} / \mathrm{cm}^{3}$ density product was observed for 16 days. To this end, the waste was poured into a transparent flask and stored without mixing. During the tests, the average density of the product was measured in different layers. It was found that when the sodium ferrosilicate production is stored, a precipitate is deposited on the bottom of the vessel, the density of which reaches $1.8 \mathrm{~g} / \mathrm{cm}^{3}$ after 12 days.

In the course of carrying out this work, the experiments were cunducted to produce slag-foam glass on the basis of standard sodium liquid glass and soluble sodium ferrosilicate. In determining the starting material composition of the slag-foam glass, fly 
ash, ash and slag mixture, liquid sodium ferrosilicate and its production waste were used. To obtain the material samples, the aggregate was mixed with the liquid component in various proportions until a homogeneous plastic mass was obtained. The resulting mixture was filled into $10 \times 10 \times 10 \mathrm{~cm}$ molds, which were kept in a drying chamber at a temperature of $170-180^{\circ} \mathrm{C}$ for $18-24$ hours. After cooling, the samples were removed from the molds and tested. It was found that the strengths and average density of the obtained samples are close in their values; the main studies were performed using liquid sodium ferrosilicate (liquid glass). In the course of experiments, the binder consumption by volume was taken as unity, and the total consumption of the aggregate was changed from 2 to 4 . The consumption of the liquid component with $1.4 \mathrm{~kg} / \mathrm{cm}^{3}$ density was taken equal to unity. Strength and average density of the samples were determined one day after their heat treatment at a temperature of $+180^{\circ}$ for $18-21$ hours.

From the analysis of the research results it was found that the samples with a composition of 4:1 (\# 40 and \# 41) have the greatest strength, but the molding mass is not sufficiently plastic at that, it does not lay down well, and large pores of 20-30 mm size are formed in the structure of slag-glass glass, which makes the material unsuitable for use. A sufficiently high strength $(7.36 \mathrm{MPa})$ is possessed by samples of a composition of $3: 1$, in which the ash-slag mixture and ferro-dust were used in equal proportions. To reduce the consumption of ferro-dust, considering that it is delivered from Novokuznetsk, and the ash and slag mixture is local Kemerovo material, the following was accepted as a working compound for further research: ash-slag mixture - 2 volumes; ferro-dust - 1 volume; sodium ferrosilicate - 1 volume. The compressive strength of slag-foam glass of such composition is $4.0-5.0 \mathrm{MPa}$ with the average density of $750-850 \mathrm{~kg} / \mathrm{m}^{3}$, which corresponds to regulatory requirements.

When studying the influence of qualitative characteristics of the sodium ferrosilicate production waste on the properties of slag-foam glass, the possibility of stabilizing the waste properties by introducing liquid sodium ferrosilicate into its composition was investigated. Waste consumption is taken as $100 \%$; the average density of waste is 1.32 $1.35 \mathrm{~g} / \mathrm{cm}^{3}$; sodium ferrosilicate $-1.49-1.5 \mathrm{~g} / \mathrm{cm}^{3}$.

According to the results obtained, it follows that in order to provide a compressive strength of 4-5 MPa, a 1.49-1.5 g/ $\mathrm{cm}^{3}$ density sodium ferrosilicate should be introduced into $1.32-1.35 \mathrm{~g} / \mathrm{cm}^{3}$ density waste in the amount of $35-40 \%$ of the volume of the latter. Adding a smaller amount of sodium ferrosilicate does not provide the required strength characteristics, and what is more - leads to a rise in the cost of the material.

The influence of the starting material heat treatment temperature for the production of the slag-foam glass of the required quality was studied in a composition of $3: 1$, where ashslag mixture ( 2 parts) and ferro-dust ( 1 part) were used as the aggregate, and as a binder waste with $35 \%$ sodium ferrosilicate additive volume. The temperature in the drying chamber varied from +110 to $+170^{\circ} \mathrm{C}$ and was cured for $18-21$ hours. During the research it was established that the optimum temperature for isothermal curing of the material should be considered the temperature of $+150-170^{\circ} \mathrm{C}$.

To determine the optimal heat treatment regime, the influence of the isothermal holding time on the properties of slag-foam glass was investigated. Samples were cured in accordance with the regime: immediately after manufacturing the molds were placed in a drying chamber; the temperature was raised to $+170^{\circ} \mathrm{C}$ in 2 hours; further, the isothermal holding time was set from 2 to 16 hours; the cooling took place together with the camera for about 5 hours. From the results of experiments, it was found that it is optimal to cure slag-foam glass at a temperature of $+150-170^{\circ} \mathrm{C}$ for $10-12$ hours. A further increase in the drying temperature or time does not lead to an increase in the strength of the materials, but will require a significant overrun of electricity. 
To study the nature of the changes in the strength characteristics of slag-glass glasses in time, twin samples were fabricated, which were subjected to heat treatment under the same conditions. Some of the samples were tested for compression one day after heat treatment, and some were stored under natural humidity conditions and tested at different curing times.

The following conclusions can be drawn from the results of the conducted studies:

1. Under condition of storage of dry samples under conditions of natural humidity (in the laboratory), the average density of samples increases by $3-58 \%$, depending on the structure of the material, the presence of pores of various shapes and sizes. The average increase in the sample density is $112.5 \%$.

2. After storage of samples under normal conditions for 28-31 days, the compressive strength is $43-261 \%$ of the strength of the samples at the age of one day. The average strength of the samples is $101 \%$ of its original value.

In Fig. 1 the strength characteristics of the slag-foam glass of 3:1 composition after heat treatment are shown.

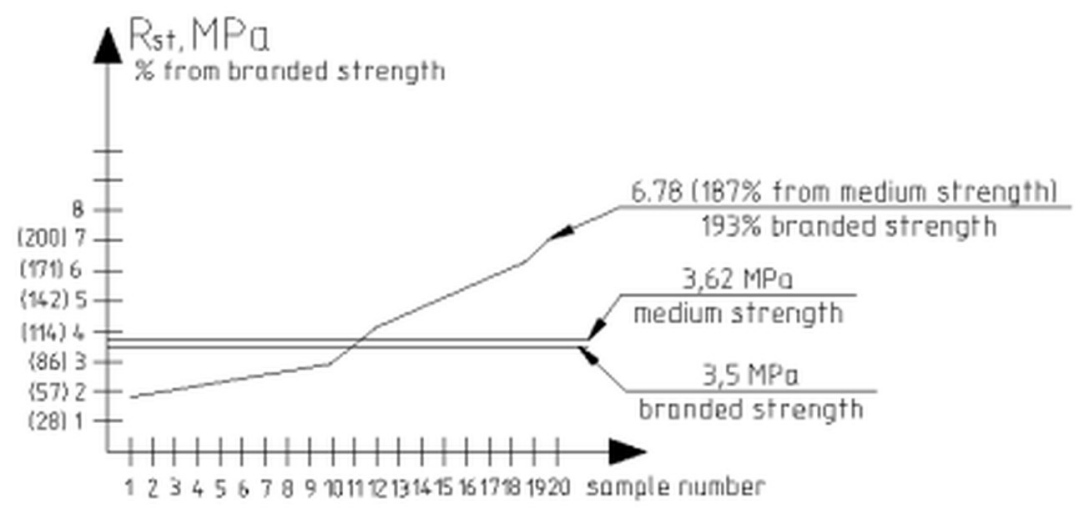

Fig. 1. Strength characteristics of slag-foam glass with a composition of 3:1 after heat treatment

In the graph shown in Fig. 1 it can be seen that the average strength of the slag-glass glass is $3.62 \mathrm{MPa}$, with a branded value of $3.5 \mathrm{MPa}$, and its minimum value is $55 \%$ of the branded strength and $53 \%$ of the average strength. This indicates that the investigated composition of concrete lies between the satisfactory and acceptable quality, and closer to the first, therefore, it can be adopted as a working value.

In the process of operation, and sometimes in the manufacturing process, building materials are exposed to various kinds of natural and artificial impacts. Considering the conditions in which slag-foam glass will be manufactured and used, in the present studies the issue of the material resistance under conditions of alternating wetting, drying, freezingthawing was considered.

The resistance of slag-foam glass to the alternate wetting and drying was determined on samples-cubes measuring $10 \times 10 \times 10 \mathrm{~cm}$. The samples were tested at the age of three days after heat treatment. Before the test, the samples were placed in water for 48 hours. The test cycle was: 6 hours - drying at a temperature of $+80-90^{\circ} \mathrm{C} ; 18$ hours - humidification at a temperature of $+20^{\circ} \mathrm{C}$. After every 5 cycles, the samples were inspected, defects were noted and tested for compression. Control samples were stored under normal conditions. From the results of the tests of slag-foam glass for wetting and drying, it is evident that already after 
5 cycles the material loses its compressive strength, which for test samples is $45 \%$ of the strength of the control ones.

The frost resistance of slag-foam glass was determined by two regimes: freezing at a temperature of $-8-20^{\circ} \mathrm{C}$ for $2( \pm 0.5)$ hours and thawing in water for $2( \pm 0.5)$ hours at a temperature of $+18^{\circ} \mathrm{C}$. Before the test, the samples were saturated with water for 48 hours. Control samples were stored under normal conditions; after 5, 10 and 15 cycles the samples were tested for compression. Taking into account the working conditions of slag-foam glass, the slag-foam glass frost resistance was determined under the conditions of alternating freezing and thawing of samples under natural humidity conditions.

According to the results of the research, it was found that after 10 cycles of alternating freezing and thawing in water, the samples of slag-glass glass lose $21 \%$, and after 15 cycles $-26 \%$ of the compressive strength. With respect to concrete, such samples are not tested for frost resistance in wet state. Slag-foam glass samples, subjected to alternate freezing and thawing under normal conditions, after 10 cycles do not lose their strength characteristics, and after 15 cycles their strength is $79 \%$ of the strength of the control cubes.

Thus, in the case of protecting the slag-foam glass from the action of humidity, the material under conditions of cyclic freezing and thawing is not destroyed.

From these studies it follows that the slag-foam glass made on the basis of the sodium ferrosilicate waste binder meets the characteristics of air binders, and the sodium ferrosilicate waste should (as expected) be classified as an air-binding agent capable of hardening and retaining strength characteristics in dry and normal humidity conditions.

\section{Results and discussion}

1. The liquid sodium ferrosilicate production waste of Kemerovo chemical enterprises is unstable. Its average density varies from $1.8 \mathrm{~g} / \mathrm{cm}^{3}$. Its composition contains up to $30 \%$ of solid precipitation and up to $60 \%$ of water. As the research has shown, this secondary product can be used as a binder for the manufacture of structural and thermal insulation material only after its mandatory homogenization and processing.

2. Homogenization of the liquid sodium ferrosilicate production waste is recommended to be done by draining it into an open container with a volume equal to seven or ten daily consumption and continuous mixing in it. The container should be replenished according to the rhythm of consumption.

3. Waste processing should be carried out by introducing into its composition up to $35-40 \%$ (by volume) of liquid sodium ferroelectric with a density of $1 / 49-1 / 5 \mathrm{~g} / \mathrm{cm}^{3}$ (specified by test mixtures). Such a minimum additive ensures that the minimum characteristics required for structural and thermal insulating wall material are achieved.

4. The processes of waste homogenization and processing should be technologically combined.

5. As the research confirmed, the liquid sodium ferrosilicate and the processed waste of its production (like soluble sodium glass) belong to air binders, which are characterized by the fact that they are able to solidify and permanently retain strength only in air.

6. Thermal calculation performed for low-rise residential buildings constructed in the climatic region of the city of Kemerovo showed that the required resistance to heat transfer of external slag-foam glass walls with the $40 \mathrm{~cm}$ thick aggregate faced with the $40 \mathrm{~cm}$ thick brick on the outside and with internal $2 \mathrm{~cm}$ plaster layer is provided at an average slag-foam glass density of less than or equal to $1000 \mathrm{~kg} / \mathrm{m}^{3}$ (in a dried to a constant density state).

7. It is found by the research that at the average density of the aggregate (Central Heating and Power Plant ash and slag mixture) equal to $800-1000 \mathrm{~kg} / \mathrm{m}^{3}$ and the fine additive (Kuznetsk ferroalloy plant ferro-dust) equal to $200 \mathrm{~kg} / \mathrm{m}^{3}$, the required average slag-foam glass density $\left(850-1000 \mathrm{~kg} / \mathrm{m}^{3}\right)$ at acceptable values of the time resistance to compression 
(3.5-5.0 MPa) and the minimum ferro-dust content in the mixture is achieved with the following volume ratio of the mixture components:

- binder: processed and homogenized (conclusions 2 and 3) the sodium ferrosilicate production waste with an average density of $\rho=1.42-1.5 \mathrm{~g} / \mathrm{cm}^{3}$ (one volume part);

- aggregate: ash and slag mixture with an average density of $800-1000 \mathrm{~kg} / \mathrm{m}^{3}$ (two volume parts);

- floured additive: ferro-dust with an average density of $200 \mathrm{~kg} / \mathrm{m} 3$ (one volume part).

8. Mixing of the slag-foam glass components is recommended to be performed in forced mixers (bladed, screw, turbulent).

9. Laying a fine-grained material composition mixture (conclusion 7) into the formwork can, without taking into account its cast consistency, be carried out without vibratory compaction.

10. Studies have shown that the optimum temperature for the blow up of the slag-foam glass of the material composition (conclusion 7) is $170^{\circ} \mathrm{C}$. A decrease in the temperature of the blow up temperature below $150^{\circ} \mathrm{C}$ leads to a sharp deterioration in the process of thermal blow up, strength characteristics, and the soluble ferro-glass concrete structure.

11. The experiments showed that the strength of the top crust after completing the thermal blowing up and the strength of the slag-foam glass is such that manual or mechanical cutting is rather difficult. It is recommended, therefore, to make the slag-foam glass products using the forced constraint of its dissolution.

12. The isothermal process the slag-foam glass strength gain according to the regime stipulated in conclusion 10 ensures the accelerated formation of the solid silicic acid gel. The process proceeds quite fully; further stay of the samples in dry or normal air does not lead to a significant increase in compressive strength (at the age of 28 days it is 1.01 , and at the age of 60 days it is not more than 1.03 ).

13. The average density of the samples in $\mathrm{kg} / \mathrm{m}^{3}$ after the isothermal strength gain process and their cooling in the closed moisture-tight chamber to a temperature of $+18-20^{\circ} \mathrm{C}$ is taken as the average density of the slag-foam glass grade (this density is assumed equal to the average density of the samples in the dried to constant mass of the state).

14. The compressive strength of slag-foam glass sample cubes of the composition specified in conclusion 7, in compliance with the technological requirements for the liquid ferrosilicate production waste homogenization and processing, according to conclusions 24 , the mixture production and thermal blowing up according to conclusions 8-10 and the determination of its strength characteristics and average density according to conclusions 12-13 (taking into account the spread) corresponds to the compression strength classes B2.5 (M35) - B3.5 (M50), and its average density $\left(850-1000 \mathrm{~kg} / \mathrm{m}^{3}\right)$ is within the limits of the average Д $900-Д 1000$ density grades.

The spread of slag-foam glass classes and its grades depends mainly on the quality characteristics of the binder - processed and homogenized waste.

The developed and recommended material composition of the slag-foam glass and its manufacturing technology, therefore, meets the regulatory requirements for lightweight concretes in terms of the ratio of their strength and average density and is within their optimal limits.

15. Studies have shown that thermally blown up slag-glass is related to air-binder cellular materials with an open, moisture-migrating character, the nature of porosity. Its use in conditions of high humidity and in wet rooms is unacceptable - it leads to a decrease in strength and heat engineering characteristics, the slag-foam glass softening, the loosening of the structure under during cyclic wetting-drying and freezing-thawing.

Therefore, the use of slag-foam glass as a material for external and internal walls should be allowed under dry and normal humidity conditions in dry climatic zones (Kemerovo is 
located in such a zone), while protecting it from episodic moistening with the measures specified in conclusion 18 below.

The open sides of internal walls should be plastered with cement or lime-cement mortar. In all cases, it is necessary to protect the inner and outer slag-foam glass walls from moisture migration from the cellar or basement. This protection in accordance with the general requirements of the standards is carried out by laying down the roll waterproofing between the pedestal and the first floor walls.

The use of slag-foam glass for wet walls is prohibited.

\section{Conclusion}

Slag-foam glass walls are prefabricated structures, produced from industrial waste, environmentally clean, biologically resistant and well preserving their properties. The technology of production of this material on the basis of liquid glass and other composites does not require significant capital costs, since it can be based on traditionally existing equipment. In the factory, larger blocks of slag-foam glass panels can be made with the exterior brick or concrete facing.

The expected economic effect is to reduce the cost of production by using cheaper materials, increasing productivity, reducing the complexity of the construction of the exterior building walls, with the exception of additional surface insulation operations.

\section{References}

1. J. Brozovsky, D. Benes, J. Zach, RILEM Bookseries, 6, 335 (2013)

2. Alessandra Gianoncelli, Annalisa Zacco, Rudolf P. W. J. Struis, Laura Borgese, Laura E. Depero, Elza Bontempi, Fly Ash Pollutants, Environmental Chemistry for a Sustainable World, 4, 103 (2013)

3. Uglyanitsa, A. V., T. V. Khmelenko, K. D. Solonin, Research India Publications, 9(22), 16837 (2014)

4. A. V. Uglyanitsa, N. V. Gilyazidinova, A. A. Zhikharev, A. A. Kargin, HRBS Journal, 10(1), 1687 (2014)

5. J. Alexandre Bogas, Rita Nogueira, KSCE Journal of Civil Engineering, 18(6), 1780 (2014)

6. A. V. Uglyanitsa, N. V. Gilyazidinova, N. Y. Rudkovskaya, T. N. Santalova, Research India Publications, 10(8), 19235 (2015)

7. A. V. Uglyanitsa, N. V. Gilyazidinova, N. Y. Rudkovskaya, T. N. Santalova, Research Journal of Applied Sciences, 10(8), 397 (2015) 